\title{
RAPID EYE MOVEMENTS DURING PARADOXICAL SLEEP IN PATIENTS WITH CEREBROVASCULAR DISEASE
}

\author{
LUCIANO RIBEIRO PINTO JR, ADEMIR BAPTISTA SILVA, SERGIO TUFIK
}

\begin{abstract}
Rapid eye movements that occur during paradoxical sleep are generated from the brainstem and are modulated by cerebral hemispheres. In an attempt to establish the participation of cerebral hemispheres on rapid eye movements, we carried out a quantitative study of eye movements density in patients bearing hemispheres vascular lesions. The polysomnographic recordings of 24 patients were compared to those of 24 healthy volunteers. Density of rapid eye movements was defined as the porcentage of eye movements during the respective time of paradoxical sleep. Based on the present results, we concluded that: stroke patients with hemispheric lesions displayed increased density of rapid eye movements; there was no difference on the density of rapid eye movements according to the hemispheric lesion; higher density of rapid eye movements was observed in patients with anterior hemispheric lesion.
\end{abstract}

KEY WORDS: rapid eye movements, paradoxical sleep, dreams, stroke.

\section{Movimentos oculares rápidos durante o sono paradoxal em pacientes com doença cerebrovascular}

RESUMO - Os movimentos oculares rápidos que ocorrem durante o sono paradoxal são gerados no tronco cerebral e modulados pelos hemisférios cerebrais. Com o objetivo de estabelecer a participação dos hemisférios cerebrais no controle destes movimentos, realizamos estudo quantitativo da densidade dos movimentos oculares em pacientes com acidente vascular cerebral. $\mathrm{O}$ registro polissonográfico de 24 pacientes com antecedente de doença cerebrovascular foi comparado com o de 24 voluntários sadios. A densidade dos movimentos oculares rápidos foi definida como sendo a porcentagem do tempo de movimentos oculares sobre o tempo de sono paradoxal. Baseados nos resultados pudemos concluir que pacientes com acidente vascular cerebral com lesões hemisféricas mostraram aumento da densidade de movimentos oculares rápidos; não houve diferença na densidade dos movimentos oculares quanto ao hemisfério comprometido; maior densidade foi observada nos pacientes com lesões hemisféricas anteriores.

PALAVRAS-CHAVE: movimentos oculares rápidos, sono paradoxal, sonhos, acidente vascular cerebral.

Paradoxical sleep events may be classified as tonic and phasic. Tonic events are continuous and may be characterized by hippocampal theta rhythm, synchronization of cerebral electrical activity and muscle atonia. Phasic events are periodic and are characterized by rapid eye movements, bursts of sawtooth waves and by ponto-geniculo-occipital waves ${ }^{1-3}$. Both, tonic and phasic events, result from the activation of gigantic cells in the pons. Eye movements occur as a consequence of phasic activation of oculomotor and vestibular system via pontine reticular formation.

Although the role of brainstem on rapid eye movements is beyond doubt, some authors suggest a hemispheric participation on different phases of sleep and, therefore, on paradoxical sleep, dreams and rapid eye movements ${ }^{4}$. Rapid eye movements may vary as a function of genetic, constitutional

Departament of Psychobiology; Universidade Federal de São Paulo (UNIFESP). This study was supported by Associação Fundo de Incentivo à Psicofarmacologia (AFIP). Aceite: 14-dezembro-1999.

Dr Luciano Ribeiro Pinto Jr. - Departamento de Psicobiologia, UNIFESP - R. Botucatu 862/1 ${ }^{\circ}$ andar - 04023062 São Paulo SP - Brasil. 
and personality factors, and, as consequence, they are considered an individual characteristic ${ }^{5,6}$. Several studies analyzed the variation of rapid eye movements density in mood disorders ${ }^{7-9}$. Gould et al. ${ }^{10}$ established the association between rapid eye movements and sleep apnea.

With in regard to the relationship between sleep and cerebrovascular disease, damage of the brainstem modifies sleep architecture, mainly the organization of paradoxical sleep ${ }^{11-17}$. There are, however, few studies investigating the relationship between encephalic vascular lesions and rapid eye movements ${ }^{18}$. Laffont et al. ${ }^{16}$ observed a reduction of ocular movements when vascular lesions are situated in the brainstem, more specifically in the medial pontine tegmentum (gigantocellular and center-caudal pontine nuclei). Doricchi et al. ${ }^{12}$ examined rapid eye movements in patients bearing hemispheric vascular lesions, who presented the unilateral negligence syndrome, in order to establish the participation of attention mechanisms on rapid eye movements. Except for the lack of rapid eye movements towards the neglected side, all other sleep parameters were similar, regardless of whether the lesion was localized in the right or left hemisphere.

In order to examine the participation of brain hemispheres on rapid eye movements during paradoxical sleep, we performed a quantitative analysis of this phasic event in patients with brain lesions of vascular nature.

\section{METHOD}

\section{Subjects}

The experimental group consisted of 24 patients, whose age varied from 32 to 69 years. These patients came from the Department of Neurology of UNIFESP, with a history of stroke, that occurred more than 30 days earlier, since we were interested in well-established vascular lesions and considering that in the acute phase brain alterations are more diffuse. All patients were submitted to a cranial computerized tomography, in order to establish the localization of the lesion. Patients who presented other neurologic diseases, as well as those who used any substance that could interfere with sleep architecture, were also excluded (Table 1).

The control group was composed by 24 healthy volunteers, whose age varied from 32 to 69 years. They did not present any sleep alterations, nor did they bear any kind of neurologic disease or used any medicine that could alter the normal sleep pattern (Table 1).

\section{Polysomnographic recordings}

Polysomnograms were performed throughout one night, with an 8-channel Grass electroencephalograph. The recordings included brain electrical activity, eye movements, chin muscle activity, nasal and oral airflow, thoracic and abdominal respiratory movements, heart beat and leg movements. The electroencephalogram used four electrodes: central left (C3), central right (C4), left ear (A1) and right ear (A2), and placement C3-A2 and C4A1, according to the international 10-20 system $^{19}$. Other electrodes placement and sleep stages classification followed the criteria established by Rechtschaffen and $\mathrm{Kales}^{20}$. The following parameters were considered: total recording time, total sleeping time, duration of non-paradoxical sleep and its four stages, duration of paradoxical sleep, total time of awakening, sleep latency, paradoxical latency, REM density, apnea/hipopnea index and heart beat.

REM density is defined as the percentage of time (in minutes) in which rapid eye movements occurred during the respective period of paradoxical sleep, considering that amplitude of eye movements its higher than $25 \mu \mathrm{V}^{18}$. Calculation of this index was made by the following equation: total duration of rapid eye movements/ total duration of paradoxical sleep x 100 .

\section{Statistical analysis}

Table 1. Characteristics of cerebrovascular patients and healthy volunteers (control) (mean \pm sd)

\begin{tabular}{lccc}
\hline & Age (years) & Male & Female \\
\hline Cerebrovascular Patients & $51.0 \pm 10.1$ & 20 & 4 \\
Control & $46.8 \pm 8.3$ & 8 & 16 \\
\hline
\end{tabular}

For statistical purposes, two groups were initially considered: control and cerebrovascular disease. After these groups were compared, cerebrovascular diseases patients were divided in bearers of left hemisphere lesions and right hemisphere lesion. For each hemisphere we contemplated lesion situated on the anterior or posterior areas. One-way ANOVA and Student'st-test were employed in the analyses of total 
Table 2. Density of rapid eye movements during all paradoxical sleep and the first paradoxical sleep period, in healthy volunteers and in cerebrovascular patients (median and semi-interquartil interval)

\begin{tabular}{lcc}
\hline & Total paradoxical sleep & Paradoxical sleep (first period) \\
\hline Cerebrovascular patients $(\mathrm{n}=24)$ & $12.4(11.0)^{*}$ & $12.9(11.1)^{*}$ \\
Control $(\mathrm{n}=20)$ & $4.5(3.1)$ & $4.8(2.4)$ \\
\hline
\end{tabular}

*significantly different from control group; $\mathrm{p}<0.05$, Mann-Whitney U test

recording time, total sleep time, sleep latency, awakenings during sleep, total duration of non-paradoxical sleep and its respective sleep stages, total duration of paradoxical sleep, paradoxical sleep latency. Analyses of sleep efficiency, REM density and apnea/hipopnea index were made by the Kruskal-Wallis Rank test and by MannWhitney U test. Correlations between density of rapid eye movements and the patient's age, time elapsed since the stroke occurred, and sleep efficiency were made by the Spierman correlation test. The level of significance was set at $\mathrm{p}<0.05$.

\section{RESULTS}

Four healthy volunteers presented sleep apnea/hipopnea, the indices of which varied from 8.2 to 11.8 /hour of sleep. In the cerebrovascular group, six patients presented respiratory alterations with indices varying from 10.1 to 59.4/hour of sleep. Statistical analysis of these parameters showed that mean index of sleep apnea/hipopnea was higher in cerebrovascular patients than in healthy

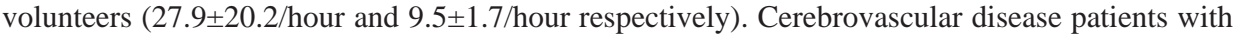
sleep apnea and hypopnea displayed shorter latency to sleep than those patients who did not present respiratory alterations.

With regard to localization of lesions, the tomography revealed their presence in the left hemisphere in eight patients, four presented lesion in anterior areas, whereas in four patients the lesions were located in posterior regions. Lesions in the right hemisphere were detected in 11 patients: in four patients, these lesions were located in anterior areas, and in seven, they were situated in posterior areas. Imaging evaluation detected lesions in both hemispheres in three patients, whereas in two, there was no evidence of brain lesions.

There were no significant correlations between REM density and the patient's or volunteer's age, and with time elapsed from the stroke, nor could we detected a correlation between REM density and sleep efficiency in either group. There was an increase in stage 1 and a reduction of stages 2 and 3 in cerebrovascular disease patients, compared to controls. Overall, however, no changes in non-paradoxical sleep and paradoxical sleep duration were detected.

Cerebrovascular patients presented increased REM density, compared to volunteers from control group. This augmented density was observed in total, as in the first paradoxical period (Table 2). No differences were detected when volunteers were compared with patients with left or right hemisphere lesion (Table 3), however, there was a significant increase of REM density in the group with anterior lesions (Table 4).

\section{DISCUSSION}

\section{Respiratory disorders in patients with cerebrovascular disease}

The mean index of sleep apnea and hipopnea was higher in cerebrovascular patients than in healthy volunteers. Respiratory alterations during sleep, characterized by an index of apnea and hipopnea above 10/hour, were observed in six patients. In three cases in which we could determine the type of respiratory disorder, one patient presented a high index of obstructive apnea (50.9/hour).

The relatioship between sleep apnea syndrome and cardiovascular alterations is well established. Askenasy and Goldhammer ${ }^{21}$ described the case of a patient who developed sleep apnea after having a 
Table 3. Density of rapid eye movements and localization of hemispheric lesion. Data are expressed as median and semi-interquartil interval)

\begin{tabular}{|c|c|c|c|c|}
\hline & $\begin{array}{c}\text { Total } \\
\text { paradoxical sleep }\end{array}$ & $\begin{array}{c}\text { Paradoxical } \\
\text { sleep (first period) }\end{array}$ & $\begin{array}{c}\text { Paradoxical } \\
\text { sleep (second period) }\end{array}$ & $\begin{array}{c}\text { Paradoxical } \\
\text { sleep (third period) }\end{array}$ \\
\hline $\begin{array}{l}\text { Control } \\
(n=24)\end{array}$ & $4.5(3.1)$ & $4.8(2.4)$ & $6.7(3.8)$ & $5.8(4.6)$ \\
\hline $\begin{array}{l}\mathrm{LBH} \\
(\mathrm{n}=7)\end{array}$ & $18.3(12.3)$ & $5.3(14.7)$ & $8.6(7.5)$ & $19.9(13.8)$ \\
\hline $\begin{array}{l}\mathrm{RBH} \\
(\mathrm{n}=8)\end{array}$ & $8.0(9.4)$ & $10.8(9.8)$ & $26.3(9.7)$ & $14.5(10.5)$ \\
\hline
\end{tabular}

LBH, left brain hemisphere; RBH, Right brain hemisphere.

Table 4. Density of rapid eye movements and localization of the lesion. Data are presented as median and semiinterquartil interval.

\begin{tabular}{lcccc}
\hline & $\begin{array}{c}\text { Total } \\
\text { paradoxical sleep }\end{array}$ & $\begin{array}{c}\text { Paradoxical } \\
\text { sleep (first period) }\end{array}$ & $\begin{array}{c}\text { Paradoxical } \\
\text { sleep (second period) }\end{array}$ & $\begin{array}{c}\text { Paradoxical } \\
\text { sleep (third period) }\end{array}$ \\
\hline $\begin{array}{l}\text { Control } \\
(\mathrm{n}=24)\end{array}$ & $4.5(3.1)$ & $4.8(2.4)$ & $6.7(3.8)$ & $5.8(4.6)$ \\
$\begin{array}{l}\text { Anterior } \\
(\mathrm{n}=5)\end{array}$ & $19.5(4.8)^{*}$ & $27.8(12.4)^{*}$ & $24.2(6.5)^{*}$ & $20.8(15.8)$ \\
$\begin{array}{l}\text { Posterior } \\
(\mathrm{n}=10)\end{array}$ & $5.9(7.8)$ & $6.2(7.0)$ & $8.5(15.6)$ & $17.1(11.6)$ \\
\hline
\end{tabular}

*significantly different from control group; $\mathrm{p}<0.05$, Kruskal-Wallis rank test, followed Mann-Whitney U test

stroke with an ischemic infarction of the lateral medulla. In the mammalian medulla there are three clusters of respiratory neurons. For a normal respiration it is vital that these nuclei modulate the vestibulocerebellar regulation of the supraglotic, genioglossus, pharyngolarynx, diaphragm and intercostal muscle tonus. The proximity between hypnogenic and respiratory somatic centers may provide an explanation for the development of sleep apnea after an infarction of the lateral region of the medulla ${ }^{21}$. Palomaki et al. ${ }^{22}$ studied 177 male patients with cerebral infarction and observed that the frequency of vascular conditions is higher in snorers than non-snorers. The authors suggest that ischemic cerebral infarction occurs more frequently during sleep, at the end of the night.

\section{Sleep architecture of patients with cerebrovascular disease}

Korner and coworkers ${ }^{15}$ studied the sleep pattern of 19 patients with cerebrovascular disease due to thromboembolism of the medial cerebral artery diagnosed by cranial computerized tomography, 14 days after the ischemic accident. Nine of these patients presented lesion in the right hemisphere and ten in the left hemisphere. Compared to a control group, composed by 13 healthy volunteers, these patients spent more time in bed, presented lower sleep efficiency, increased time of nonparadoxical sleep, as a result of increased time of stages 1 and 4 , and reduction of paradoxical sleep. Our results showed that cerebrovascular patients present an increased time of stage 1, however, without differences in paradoxical sleep.

Another study with 18 cerebrovascular patients, whose ischemia occurred at the level of the medial cerebral artery and five hours before the onset of symptoms, reported reduction of paradoxical sleep, proporcional to the severity of the neurological features and depth of the lesion. On the third 
week following the ischemia, the authors observed normalization of paradoxical sleep ${ }^{13}$. Three of our patients did not display paradoxical sleep and their lesions were located in deep regions of the brain hemisphere. It has been suggested that during the acute phase that follows ischemic cerebrovascular disease, the disappearance of paradoxical sleep may be a consequence of the suppression of eye movements and sawtooth waves, and persistency of the muscle tonus indicating that paradoxical sleep generator is still active.

\section{Rapid eye movements in patients with cerebrovascular disease}

The cerebrovascular patients presented augmented REM density, when we considered both total paradoxical sleep and the first paradoxical period. According King et al. ${ }^{18}$ patients with neurologic disorders, other than vascular disease do not present altered REM density, compared to normal controls, however, augmented REM density is reported to occur in depressive patients ${ }^{7-9}$.

An inverse relationship between REM density and sleep depth has been suggested. Feinberg et al. ${ }^{23}$ observed a reduction of REM density in ten healthy volunteers after one night of sleep deprivation, and interpreted this result as a consequence of increased sleep depth. If this were true, augmented REM density in cerebrovascular patients should be due to a more superficial sleep. We did not, however, find any correlation between REM density and sleep efficiency.

Considering the localization of brain lesion, our results showed that REM density was augmented in patients whose brain lesions were located in anterior regions, compared to control subjects. This increased REM density may be due to cortical lesions that could, in turn, induce eye movements, generated in the brainstem ${ }^{11,24}$. In cats, frontal cortex lesions suppress isolated eye movements, originated in the cortex, however, eye movements that occur in burst, generated in the brainstem, are augmented. On the contrary, occipital lesions reduce the bursts of eye movements. Jeannerod et al. ${ }^{24}$ suggested a facilitation role for the the occipital lobe and an inhibitory role for the frontal lobe on rapid eye movements. Appenzeller and Fischer ${ }^{11}$ also proposed a facilitation role for the visual cortex and an inhibitory influence of the frontal cortex on REM density. Similarly, two patients with atrophy of the frontal brain presented high REM density, leading King et al. ${ }^{18}$ to suggest the frontal cortex plays an inhibitory role on eye movements.

Doricchi and coworkers ${ }^{12}$ studied rapid eye movements in patients with left unilateral negligence syndrome, due to lesions on the right hemisphere, and found a suppression of eye movements toward the neglected side. They concluded that attention mechanisms, located in parietal lobes, influence rapid eye movements during sleep.

The rapid eye movements, the cortical areas and dreams

A more relevant participation of posterior brain areas on rapid eye movements was suggested by studies that employed neurophysiologic methods ${ }^{25,26}$. Indirect evidence for the involvement of posterior regions on paradoxical sleep was obtained with analysis of the ability to recall dreams following encephalic lesions $\mathrm{s}^{27-30}$. Murri and coworkers ${ }^{30}$ studied a group of 53 patients with focal lesions of either vascular or neoplastic nature. The patients with posterior lesions showed more difficulty to recall dreams, associated with a performance deficit in visual-perceptive tests, than patients with anterior lesions. These results were recently confirmed. Doricchi and Violani ${ }^{31}$ hypothesized that inability to recall dreams is a consequence, not only of the the loss of memory and verbal impairment, but also of a deficit of cognitive dream decoding, since the lesions impair cognitive processes related to speech, which is essential for processing internal information. Murri et al. ${ }^{32}$ showed, more specifically, that patients with posterior lesions, on temporal, occipital and parietal lobes, mainly in the right hemisphere, presented more difficulty to recall dreams.

Our results did not indicate greater influence of either hemisphere on REM density, since patients did not differ from normal volunteers in this respect. Several authors have reported the higher specialization of the right hemisphere as regards paradoxical sleep, specially concerning its 
main role in the genesis of dreams ${ }^{33-35}$. Neurophysiological studies, employing analysis of amplitude of each brain hemisphere electrical activity during sleep, showed greater participation of the right hemisphere ${ }^{35}$. Similar results were reported with tests of hemisphere function after awakening from paradoxical sleep. Tests of tactile recognition after each sleep phase demonstrated the major importance of the right hemisphere during paradoxical sleep ${ }^{36}$. More recently, the same authors emphasized that, although the right hemisphere plays a major role in spatial tests, there is no consistent evidence that it is more active during paradoxical sleep. Reinsel and Antrobus ${ }^{37}$ did not observe hemisphere lateralization, using specific tests for each hemisphere, after awakening from either non-paradoxical or paradoxical sleep. Similarly, Armitage et al.$^{38}$ did not find support in the literature for the hypothesis of greater influence of the right hemisphere on paradoxical sleep. Hobson et al. ${ }^{39}$ related that during paradoxical sleep occurs an activation of the pontine brain stem and of limbic and paralimbic cortical structures involved in mediating emotion and a corresponding deactivation of dorsolateral prefrontal cortical structures involved in the executive and mnemonic aspects of cognition.

\section{CONCLUSION}

Our results, togheter with previous reports, suggest that cortical and subcortical structures, particularly in frontal regions of both hemispheres, exert an inhibitory influence on rapid eye

movements generated from the brainstem. If dreams were related to eye movements, we could hypothesize that both phenomena are triggered by structures located in the brainstem and modulated by brain hemisphere. This hypothesis does not exclude the psychological content of dreams, that could be generated from cortical structures responsible for emotion.

\section{REFERENCES}

1. McCarley RW, Winkelman JW, Duffy FH. Human cerebral potentials associated with REM sleep rapid eye movements: link to PGO waves and waking potentials. Brain Res 1983;274:359-364.

2. Niiyama Y, Shimizu T, Abe M, Hishikawa Y. Phasic EEG activities associated with rapid eye movements during REM sleep in man. Electroenceph Clin Neurophysiol 1988;70:396-403.

3. Schwartz BA. EEG et movements oculaires dans le sommeil de nuit. Electroenceph Clin Neurophysiol 1962;14:126-128.

4. Roffwarg HP, Dement WC, Muzio JN, Fischer C. Dream imagery: relationship to rapid eye movements of sleep. Arch Gen Psychiatry 1962;7:235-258

5. Linkowski P, Kerkhofs M, Hauspie R, Susanne C, Mendlewicz J. EEG sleep parterns in man: a twin study. Electroenceph Clin Neurophysiol 1989;73:279-284.

6. Cohen DB. Changes in REM dream content during the night: implication for a hypothesis about changes in cerebral dominance across REM periods. Percept Motor Skills 1977;44:1267-1277.

7. Foster FG, Kupfer DJ, Coble P, MacPartland RJ. Rapid eye movements sleep density. Arch Gen Psychiatry 1976;33:1119-1123.

8. Kupfer DJ, Broudy D, Coble P, Spiker D. EEG sleep and affective psychosis. J Affect Disord 1980;2:17-25.

9. Kupfer DJ, Foster FG, Coble P, McPartland RJ, Ulrich R. The application of EEG sleep for the differential diagnosis of affective disorders. Am J Psychiatry 1978; 135:69-74.

10. Gould GA, Gugger M, Molloy J, Tsara V, Shapiro CM, Douglas NJ. Breathing pattern and eye movement density during REM sleep in humans. Am Rev Respir Dis 1988; 138:874-877.

11. Appenzeller O, Fischer AP. Disturbance of rapid eye movements during sleep in patients with lesions of the nervous system. Electroenceph clin Neurophysiol 1968;25:29-35.

12. Doricchi F, Guariglia C, Paolucci S, Pizzamiglio L. - Disturbances of the rapid eye movements (REMs) of REM sleep in patients with unilateral attentional neglect: clue for the understanding of the functional meaning of REMs. Electroenceph clin Neurophysiol 1993;87:105-106.

13. Giubillei F, Ianinilli M, Pierallini A, Sacchetti ML, Antonini G, Fieshci C. Sleep patterns in acute ischemic stroke. Acta Neurol Scand 1992;86:567-571.

14. Hachinski VC, Mamelak M, Norris JW. Sleep architecture and recovery from stroke. In Masland RL. Portera-Sanchez G, Toffano G (eds) Neuroplasticity: a new therapeutic tool in the CNS pathology. Fidia Research Series, vol 12, Padova: Liviana Press, 1987:179-184.

15. Korner E, Flooh E, Reinhart B, et al.. Sleep alterations in ischemic stroke. Eur Neurol 1986; 25(Suppl 2):104-110.

16. Laffont F, Toffol B, Cathala HP. A syndrome of REM and non-REM sleep reduction and lateral gaze paresis after medial tegmental pontine stroke. Arch Neurol 1988;45:1236-1242.

17. Lavie P, Pratt H, Scharf B, Peled R, Brown J, Localized pontine lesion: nearly total absence of REM sleep. Neurology 1985;34:118-120.

18. King D, Akiskal HS, Lemmi H, Wilson W; Belluomini J. Yerevanian BI. REM density in the differential diagnosis of psychiatric from medical-neurological disorders: a replication. Psychiatry Res 1981; 5:267-276.

19. Jasper H. The ten-twenty electrodes system of the International Federation. Electroenceph Clin Neurophysiol 1958;10:371-375. 
20. Rechtschafen A, Kales A. A manual of standarlized terminology, techniques and scoring system for sleep stages of human subjects. Los Angeles: UCLA Brain Information Service (Brain Research Institute), 1968.

21. Askenasy JJM. Goldhammer I. Sleep apnea as a feature of bulbar stroke. Stroke 1988; 19:637-639.

22. Palomaki H, Partinen M, Erkinjuntti T, Kaste M. Snoring, sleep apnea syndrome, and stroke. Neurology 1992;42:75-82.

23. Feinberg I, Floyd TC, March JD. Effects of sleep loss on delta (0,3-3 Hz) EEG and eye movement density: new observations and hypotheses. Electroenceph Clin Neurophysiol 1987; 67:217-221.

24. Jeannerod DM, Mouret J, Jouvet M. Étude de la motricité oculaire au cours de la phase paradoxale du sommeil chez le chat. Electroenceph Clin Neurophysiol 1965;18:554-566.

25. Lu ST, Kajola M, Joutsiniemi SL, Knuutila J, Hari R. Generator sites of spontaneus MEG activity during sleep. Electroenceph Clin Neurophysiol 1992;82:182-196.

26. Miyauchi S, Takino R, Fukuda H, Torii S. Electrophysiological evidence for dreaming: human cerebral potentials associated with rapid eye movement during REM sleep. Electroenceph Clin Neurophysiol 1987;66:383-390.

27. Cathala HP, Laffont F, Sikson M, et al. Sommeil et reve chez des patients atteints de lésions pariétales et frontales. Rev Neurol 1983;139:497-508.

28. Epstein AW. Effect of certain cerebral hemispheric disease on dreaming. Biol Psychiatry 1979; 14:77-93.

29. Kerr NH, Foulkes D. Right hemispheric mediation of dream visualization: a case study. Cortex 1981;17:603-610.

30. Murri L, Arena R, Siciliano G, Mazzotta R, Muratorio A. Dream recall in patients with focal cerebral lesions. Arch Neurol 1984;41:183-185.

31. Doricchi F, Violani C. Dream recall in brain-damaged patients: a contribution to the neuropsychology of dreaming through a review of the literature. In Antrobus JS Bertini M (eds). Neuropsychology of sleep dreaming. Heilsdale: Lawrence Erlbaum Assoc Publ, 1992:99-140.

32. Murri L Bonanni E. Stefanini A, Goldstein L, Navona C, Denoth F. Neurological approaches the dream problem. In Antrobus JS Bertini M (eds.). Neuropsychology of sleep dreaming. Heilsdale, Lawrence Erlbaum Assoc Publ, 1992: 87-98.

33. Bertini M, Violani C. Cerebral hemispheres, REM sleep and dream recall. Res Comm Psychol, Psychiatry Behav 1984;9:3-14.

34. Gabel S. The right hemisphere in imagery, hypnosis, rapid eye movement, sleep and dreaming. J Nerv Ment Dis 1988;176:323-331.

35. Goldstein L, Stoltzfus NW, Gardocki JF. Changes in interhemispheric amplitude relationships in the EEG during sleep. Psysiol Behav 1972;8:811-815.

36. Bertini M, Violani C. The postwakening testing technique in the investigation of cognitive asymmetries during sleep. In Antrobus JS Bertini M (eds.). Neuropsychology of sleep dreaming. Heilsdale: Lawrence Erlbaum Assoc Publ, 1992:47-62.

37. Reinsel RA. Antrobus J. Lateralized task performance after awakening from sleep. In Antrobus JS Bertini M (eds.). Neuropsychology of sleep dreaming. Heilsdale: Lawrence Erlbaum Assoc Publ, 1992:63-85.

38. Armitage R, Hoffman R, Moffit A. Interhemispheric EEG activity in sleep and wakefulness: individual differences in the basic activity cycle. In Antrobus JS Bertini M (eds.). Neuropsychology of sleep dreaming. Heilsdale: Lawrence Erlbaum Assoc Publ, 1992:17-45.

39. Hobson JA, Steckgold R, Pace-Schott EF. The neuropsychology of REM sleep dreaming. NeuroReport 1998;9:1-14. 